\title{
APLICAÇÃO FOLIAR DE CÁLCIO E BORO A BASE DE CLORETO DE CÁLCIO E ÁCIDO BÓRICO MISTURADO NO TANQUE PARA AVALIAÇÃO DE REDIMENTO DA SEMENTE DE SOJA
}

\author{
ARANTES, Rafael Pereira ${ }^{1}$ \\ CURY, Tadeu Nascimento ${ }^{2}$ \\ LEÃO, Fabiana de Paula ${ }^{3}$ \\ MACIEL JUNIOR, Vinicius Antonio ${ }^{4}$
}

Recebido em: 2009-05-06

Aprovado em: 2009-09-29

ISSUE DOI: $10.3738 / 1982.2278 .206$

RESUMO: O experimento foi realizado no município de Ituverava, na fazenda Estiva no ano agrícola de 07/08. O trabalho utilizou a cultivar de soja BRS Valiosa RR com objetivo de avaliar o nível de rendimento da soja com aplicação de cloreto de cálcio á $26 \%$ e ácido bórico á $17 \%$ em diferentes estágios de desenvolvimento da cultura. Os tratamentos constituíram de aplicações em oito etapas, sendo: préflorada, pré-florada + floração, pré-florada + floração + vagem, pré - floração + vagem, floração, floração + vagem, vagem e testemunha. A avaliação utilizou o delineamento experimental de bloco ao acaso com 8 tratamentos e 4 repetições. Foi avaliado o número de vagem por planta, número de grão por vagem, peso de 100 grãos. Observou-se que aplicação de cloreto de cálcio e ácido bórico via foliar nos diferentes estágios de desenvolvimento da soja não mostraram diferença significativa.

Palavras - chave: Soja. Adubação foliar

\section{FOLIAR APPLICATION CALCIUM AND BORON-BASED CALCIUM CHLORIDE AND BORIC ACID MIXED ON INCOME TANK FOR THE EVALUATION OF SOYBEAN SEED}

SUMMARY: The experiment was conducted in the municipality of Ituverava, in the Estiva farm in the agricultural year of $07 / 08$. The work used the soybean cultivar BRS Valiosa RR to evaluate the performace of the soybean with application of calcium chloride to $26 \%$ and boric acid to $17 \%$ in different stages of development of culture. The treatments consisted of applications in eight steps, as follows: prebloom, pre-bloom + flowering, pre-bloom + flowering + pod, pre - bloom + pod, bloomed, flowering + pod, pods and control. The evaluation used the experimental design of randomized blocks with 8 treatments and 4 replicates. It was evaluated the number of pods per plant, number of grain per pod, weight of 100 grains. It was observed that application of calcium chloride and boric acid by leaf in the different stages of development of soybean showed no significant difference.

Keywords: Soybean. Foliar fertilization

\footnotetext{
${ }^{1}$ Acadêmico do curso de Agronomia da Faculdade Dr. Francisco Maeda da Fundação Educacional de Ituverava/FEI. Rodovia Jerônimo Nunes Macedo km 1, CEP 14500-000, Ituverava-SP.

${ }^{2}$ Engenheiro Agrônomo pela Faculdade Dr. Francisco Maeda da Fundação Educacional de Ituverava/FEI. Rodovia Jerônimo Nunes Macedo km 1, CEP 14500-000, Ituverava-SP.

${ }^{3}$ Engenheira de Alimentos pela Universidade Federal de Viçosa-MG.

${ }^{4}$ Mestre em Agronomia, Coordenador do Curso de Agronomia da FE/FAFRAM.
} 


\section{INTRODUÇÃO}

A cultura da soja representa a maior área cultivada no país, superando as tradicionais culturas do milho e cana-de-açúcar. Analisando a produtividade media do Brasil, ou seja, aproximadamente 40 sacas/ha, observa-se que a mesma ainda esta muito aquém do potencial de produção atingido pela pesquisa e por bons produtores. Dentre os fatores de produtividade, o manejo químico do solo associado a fatores climáticos e ainda o que mais limita a produtividade.

Nas fases de pré-floração a planta acumula somente cerca de $25 \%$ de matéria seca final e nutriente, atingiu aproximadamente $50 \%$ de sua altura final e desenvolveu cerca de metade do numero de nós. Esse período marca o inicio de um período de rápido e acumulo diário de matéria seca e de nutrientes essenciais para o desenvolvimento das vagens. Essa rápida acumulação de matéria seca e nutrientes pela planta inteira inicia-se nas partes vegetativas (folhas, hastes, pecíolos e raízes), deslocando-se gradualmente para as vagens e sementes em formação.

Os baixos teores de matéria orgânica no solo realçam a deficiência de micronutriente no solo como: boro(B), zinco $(\mathrm{Zn})$, molibdênio (Mo) e cobre $(\mathrm{Cu})$ (EMBRAPA, 1999). A carência de boro e muito comum no país, particularmente em solos arenosos e pobres em matéria orgânica (MALAVOLTA, 1985)

$\mathrm{O}$ elemento químico $\mathrm{Ca}$, assim como o $\mathrm{B}$, são imóveis no floema e não se redistribuem na planta, assim a deficiência nutricional de ambos se apresenta em órgãos mais novos ( MALAVOLTA, 1976,1985) As principais funções do Ca na planta são: atuar na formação do pectato de cálcio, presente na lamela media da parede celular e na germinação do grão de pólen e crescimento do tubo polínico. O B e importante na translocação de açúcares e formação da parede celular. Para Rosolem et al.(1990), o cálcio atua decisivamente no numero de flores e vagens abortadas em soja, e existe alta correlação negativa entre o teor de Ca na planta e número de flores e vagens abortada. Há relatos de aumento da produtividade de algumas culturas com o uso de bórax e outros micronutrientes.

Neste experimento, estudou-se a resposta de adubação de cloreto de cálcio e acido bórico em diferentes fases de desenvolvimento. $\mathrm{O}$ objetivo deste trabalho foi avaliar a influencia da adubação foliar através de cloreto de cálcio e acido bórico na produção de soja em diferentes fase de desenvolvimento da cultura. 


\section{MATERIAL E MÉTODO}

O experimento foi localizado no município de Ituverava, na fazenda Estiva em condições de campo, onde a precipitação anual no período do experimento foi de $1.325 \mathrm{~mm}$.

As parcelas foram divididas em $12 \mathrm{~m}^{2}(6 \mathrm{~m} \times 2 \mathrm{~m})$, sendo cada parcela com 5 linhas, com área útil de $8 \mathrm{~m}^{2}(4 \mathrm{~m} \times 1 \mathrm{~m})$ compostas das duas linhas centrais, com espaçamento de $0,50 \mathrm{~cm}$; retirando 5 plantas por linha no total de 10 plantas por parcelas.

As pulverizações foram realizadas com bomba costal de 20 litros, onde os produtos foram diluídos e aplicados com bico tipo cone de serie TT -110 - 03 com vazão de 2001/ha mantido com válvula de pressão constante.

O plantio realizado foi plantio direto em palhada de cana - de - açúcar, com espaçamento de 0,50 cm com densidade de 300.000 sementes por metro linear, com stand final de 260.000 plantas por metro. A cultivar utilizada foi BRS valiosa RR, semeada em 20/11/2007.

Os dados das aplicações estão na tabela 01 a seguir:

TABELA 1: Dados de aplicação

\begin{tabular}{|c|c|c|}
\hline \multicolumn{2}{|c|}{ Data de Aplicação } & Aplicação \\
\hline 16/01/2008 & $\begin{array}{r}\text { Pré - } \\
\bullet \\
\bullet \\
\bullet\end{array}$ & $\begin{array}{l}\text { oração } \\
\text { Pré-florada (Pré-mistura) Cloreto de Cálcio 39.23gr / Acido Bórico 12gr } \\
\text { Pré-florada + florada + vagem (Pré-mistura) Cloreto de Cálcio 13.08 gr / Acido } \\
\text { Bórico } 4 \mathrm{gr} \\
\text { Pré-florada + florada (Pré-mistura) Cloreto de Cálcio } 19.62 \mathrm{gr} / \text { Acido Bórico } 6 \\
\text { Pré-florada + vagem (Pré-mistura) Cloreto de Cálcio } 19.62 \mathrm{gr} / \text { Acido Bórico } 6 \text { g }\end{array}$ \\
\hline $01 / 02 / 2008$ & Flora & $\begin{array}{l}\text { ão plena (80\%) } \\
\text { Florada (Pré-mistura) Cloreto de Cálcio 39.23gr / Acido Bórico 12gr } \\
\text { Pré-florada + florada + vagem (Pré-mistura) Cloreto de Cálcio 13.08 gr / Acido } \\
\text { Bórico } 4 \text { gr } \\
\text { Pré-florada + florada (Pré-mistura) Cloreto de Cálcio } 19.62 \text { gr / Acido Bórico } 6 \\
\text { gr } \\
\text { Florada + vagem (Pré-mistura) Cloreto de Cálcio } 19.62 \text { gr / Acido Bórico } 6 \text { gr }\end{array}$ \\
\hline 28/02/2008 & & $\begin{array}{l}\text { m com } 3 \text { a } 5 \text { mm } \\
\text { Vagem (Pré-mistura) Cloreto de Cálcio 39.23gr / Acido Bórico 12gr } \\
\text { Pré-florada + florada + vagem (Pré-mistura) Cloreto de Cálcio 13.08 gr / Acido } \\
\text { Bórico } 4 \text { gr } \\
\text { Pré-florada + vagem (Pré-mistura) Cloreto de Cálcio } 19.62 \text { gr / Acido Bórico } 6 \\
\text { gr } \\
\text { Florada + vagem (Pré-mistura) Cloreto de Cálcio } 19.62 \text { gr / Acido Bórico } 6 \text { gr }\end{array}$ \\
\hline
\end{tabular}

Nucleus, v.6, n.2, out. 2009 
Os cálculos para adubação foram baseados nos teores encontrados na análise de solo, onde foi calculado com base no Boletim 100 para adubação de plantio para produtividade de $3000 \mathrm{~kg} / \mathrm{ha}$. (RAIJ, 1996).

A formulação foi 04-20-20 com a quantidade de $250 \mathrm{~kg} / \mathrm{ha}$ e com 30 dias após o plantio foi realizado a cobertura a lanço com $25 \mathrm{~kg} / \mathrm{ha}$ de $\mathrm{KCl}$.

A colheita foi realizada no dia 26/04/2008, 158 dias após o plantio e o processo foi manual através do arranquio das 10 plantas localizada na área útil do experimento, descartado as linha laterais e o começo e final de cada linha.

A avaliação constituiu a partir das 10 plantas de cada parcela, realizando a contagem do número de vagem, número de semente e peso de 100 sementes, sendo retirado a umidade dos grãos e corrigido para $14 \%$.

\section{RESULTADO E DISCUSSÃO}

Analisando os resultados dispostos na Tabela 02, observa-se que não houve diferenças significativas para número de vagens, número de sementes por vagem e peso de 100 sementes.

TABELA 2: Análise de variação do experimento

\begin{tabular}{lccr}
\hline \multicolumn{1}{c}{ Tratamento } & $\begin{array}{c}\text { Número de } \\
\text { Vagem }\end{array}$ & $\begin{array}{c}\text { Número de } \\
\text { grãos por vagens }\end{array}$ & $\begin{array}{r}\text { Peso de 100 } \\
\text { sementes (g) }\end{array}$ \\
\hline Pré florada & $53.7000 \mathrm{a}$ & $105.6250 \mathrm{a}$ & $2.2500 \mathrm{a}$ \\
Pré florada + florada & $55.7750 \mathrm{a}$ & $105.6500 \mathrm{a}$ & $2.5000 \mathrm{a}$ \\
Pré florada + vagem & $54.3500 \mathrm{a}$ & $106.7250 \mathrm{a}$ & $2.5750 \mathrm{a}$ \\
Pré florada + florada + vagem & $56.0750 \mathrm{a}$ & $106.2250 \mathrm{a}$ & $2.8000 \mathrm{a}$ \\
Florada & $50.6500 \mathrm{a}$ & $97.3500 \mathrm{a}$ & $2.4000 \mathrm{a}$ \\
Florada + vagem & $54.2000 \mathrm{a}$ & $107.0000 \mathrm{a}$ & $2.1250 \mathrm{a}$ \\
Vagem & $54.7750 \mathrm{a}$ & $118.9250 \mathrm{a}$ & $2.4750 \mathrm{a}$ \\
Testemunha & $58.6000 \mathrm{a}$ & $114.6250 \mathrm{a}$ & $2.9000 \mathrm{a}$ \\
\hline
\end{tabular}

Rosolem et al (1989), diz que "as aplicações até a época do florescimento podem provocar aumento no número de grãos por vagem e número de vagens por planta, assim como pequeno aumento no peso de 100 grãos".

No trabalho realizado com cloreto de cálcio e acido bórico misturado na bomba de pulverização, não mostraram vantagens em alterações de época de aplicação da fase de desenvolvimento da cultura. 


\section{CONCLUSÃO}

Os resultados encontrados nos tratamentos em condições de campo e de alteração nas épocas de aplicação do adubo foliar e fases de desenvolvimento não apresentaram resultados significativos em relação à produção.

\section{REFERÊNCIA}

ARAUJO, S. A et al. Cultura do feijoeiro comum no Brasil. Piracicaba: Potafos, 1996.

BOARETTO, A. E. et al. Absorção foliar e translocação de cálcio pelo feijoeiro. Científico, São Paulo, v.11, p 227-237. 1983

CASTRO P.R.C.; KLUGE, R. A.; PERES, L. E. P. Manual de fisiologia vegetal. Piracicaba: Agronômica Ceres, 2005.

CAMARGO, P. N.; SILVA, O. Manual de adubação foliar. São Paulo: Herba, 1975.p. 210

EMBRAPA, Empresa Brasileira de Pesquisa Agropecuária. Centro Nacional de Pesquisa de Soja. Recomendação técnicas para a cultura de soja no Paraná 1999/2000. Londrina, 1999. 236p. (Embrapa soja. Documento, 131).

MALVOLTA, E. Nutrição de plantas. Fisiologia vegetal. São Paulo: EDUSP, 1985. V. 1, 400 p.

MALAVOLTA, E. Manual de calagem e adubação das principais culturas. São Paulo: Agronomia Ceres, 1987.

ROSOLEM, C.A.; Boaretto, A. E.; NAKAGAMA, J. Adubação foliar do feijoeiro. VIII. Fontes e doses de cálcio. Cientifica, São Paulo, v.18, p. 9-14. 1991 
